\title{
Áreas urbanas de preservação permanente ocupadas irregularmente
}

\author{
Ana Cláudia Duarte Pinheiro ${ }^{1}$ \\ Juliana Barata Procópio ${ }^{2}$
}

\begin{abstract}
Resumo
0 presente artigo consiste na revisão da monografia apresentada ao Curso de Direito da Universidade Estadual de Londrina, como requisito parcial para a obtenção do título de Bacherel em Direito da acadêmica Juliana Barata Procópio, sob orientação da Professora Mestre Ana Claudia Duarte Pinheiro. O trabalho pretende analisar a questão das áreas de preservação permanente (APPs) em cidades e as ocupações que são realizadas nestas regiões, cuja proteção especial é devida pela função ambiental que exercem e não deveria haver qualquer ocupação. Contudo, a realidade apresentada nas cidades brasileiras é destoante e constantemente depara-se com ocupações irregulares em APPs em desacordo com a legislação existente; ora por falta de consciência da população acerca da importância ambiental da área, ora por políticas públicas inadequadas ou inexistentes. Tais ocupações são atingidas por problemas sócio-ambientais inerentes da irregularidade, como saneamento básico, condições de salubridade e de habitabilidade, ausência de vias de acesso seguras, dentre outros. Estes problemas ferem princípios constitucionais, como dignidade humana, direito à saúde, que tendem a agravar caso não seja dada uma solução às ocupações. Em 2006, 0 Conselho Nacional do Meio Ambiente (CONAMA) editou a resolução no 369/2006 que aponta algumas hipóteses de supressão ou intervenção em APPs - que serão de extrema importância para evitar novas ocupações irregulares e ilegais; e ainda prevê a regularização fundiária sustentável como passivo ambiental que o Estado deve à população e que se apresenta como um instrumento para assegurar à população a garantia de seus direitos e a garantia dos direitos ambientais.
\end{abstract}

Palavras-Chave: Áreas de preservação permanente; Ocupação urbana irregular; Resolução do CONAM A n. 369/06; Regularização fundiária.

\section{Introdução}

Nas áreas de preservação permanente (APPs), em tese, não deveria haver ocupação, contudo, essa não é a realidade constatada em muitas cidades brasileiras. Vários fatores a serem abordados no desenvolvimento do presente trabalho explicam esta situação.

1 Mestre em Direito Negocial pela UEL, professora de Direito Ambiental e Urbanístico para o Curso de Direito da UEL - professora orientadora do Trabalho de Conclusão de Curso apresentado.

2 Acadêmica do 5o ano do Curso de Direito da Universidade Estadual de Londrina - UEL - PR, membro da ONG MAE - M eio Ambiente Equilibrado. 
São ocupações que ocorrem sem qualquer planejamento e, por não se enquadrarem nas normas legais, nascem suportando as conseqüências da irregularidade, como carência de saneamento básico eficiente e de diversos fatores de salubridade essenciais; resultados principalmente da falta de políticas públicas no sentido de elaborar adequado planejamento urbano, e que tendem a se agravar caso mantenham-se na irregularidade. Por isso, necessário se faz uma análise das causas que explicam esta situação e das possíveis soluções para os problemas que se apresentam.

\section{Proteção jurídica ao meio ambiente}

A crescente demanda pela utilização dos bens ambientais e 0 intenso desenvolvimento econômico propulsou o movimento, que se alastrou mundialmente, a lutar pela defesa eficaz do uso moderado do meio ambiente para evitar a devastação descontrolada e escassez de seus bens; o que acarretaria na extinção das condições essenciais à vida.

Este impasse ainda se faz presente até os dias atuais e, como bem pondera Orci Paulino Bretanha Teixeira:

[...] o desafio da humanidade é conciliar o desenvolvimento com a proteção e a preservação ambiental, para não inviabilizar a qualidade de vida das futuras gerações, da coletividade e o exercício de propriedade sobre os bens ambientais (TEIXEIRA, 2006, p. 21).

Diante deste quadro, o Direito ambiental surge, não apenas para regulamentar os elementos ambientais, mas principalmente a qualidade destes.

A conquista por uma vida saudável consiste na garantia dos bens essenciais à sadia qualidade de vida, que nada mais é que a satisfação dos fundamentos democráticos impostos na Constituição Federal, como o da dignidade da pessoa humana e da isonomia.

A natureza jurídica do bem tutelado pelo Direito Ambiental é classificada como transindividual e difusa. A primeira por ser direito de cada pessoa e, ao mesmo tempo, não somente dela, mas de todos. Já a natureza difusa é por conta de os titulares serem pessoas indefinidas, uma coletividade indeterminada, não se esgotando em um único ser (MACHADO, 2005, p. 116). 
E foi pensando na proteção atribuída ao meio ambiente e a conciliação do uso dos recursos ambientais pelo homem, que o Direito Ambiental dotou de tutela especial algumas áreas em relação à interferência humana, a fim de garantir a integridade destas regiões, devido à importância ambiental relevante. É o caso das áreas de preservação permanente.

\section{Áreas de preservação permanente}

0 dispositivo constitucional relativo ao meio ambiente, art. 225, atribui, em seu § 1ํ, III, ao Poder Público o dever de "definir, em todas as unidades da Federação, espaços territoriais e seus componentes a serem especialmente protegidos, sendo a alteração e a supressão permitidas somente através de lei, vedada qualquer utilização que comprometa a integridade dos atributos que justifiquem sua proteção".

Anteriormente à Constituição de 1988, o Código Florestal, Lei no 4.771/65, já previa proteção especial a algumas áreas, delimitando seus parâmetros.

Verifica-se, por força da norma inscrita na Carta Magna, que o Constituinte, ao deixar a critério do legislador infraconstitucional o estabelecimento dos parâmetros de áreas especialmente protegidas, recepcionou integralmente o Código Florestal vigente e constitucionalizou a proteção especial dada a tais espaços, em razão deste já definir alguns limites (MARCHESAN, 2005, p. 28).

O objeto de tutela do Código Florestal são as florestas existentes no território nacional e as demais formas de vegetação, reconhecidas de utilidade às terras que revestem. A necessidade de protegê-las adveio após constatar sua crescente degradação. São caracterizadas como bens de interesse comum a todos os habitantes do País, e os direitos de propriedade sobre estas devem ser exercidos ressalvadas as limitações impostas pela legislação em geral e pelo Ordenamento Florestal.

o motivo dado por Machado para a caracterização das florestas e demais vegetações como bem de interesse comum é satisfatória:

Todos temos interesse nas florestas de propriedade privada e nas florestas de propriedade pública. A existência das florestas não passa à margem do direito e nem se circunscreve aos interesses de seus proprietários diretos. [...] 0 interesse comum na existência e no uso adequado das florestas está ligado, com forte vínculo, à função social e ambiental da propriedade (MACHADO, 2005, p. 718). 
E, com fundamento na função ambiental destes espaços, explica:

[...] Sem florestas não haverá água, não haverá fertilidade do solo; a fauna depende da floresta, e nós - seres humanos - sem florestas não viveremos. As florestas fazem parte de ecossistemas, onde os elementos são interdependentes e integrados (MACHADO, 2005, p. 719).

Por isso, o Código Florestal estabeleceu dois instrumentos de proteção a florestas e algumas vegetações específicas previstas neste ordenamento: as áreas de preservação permanente (APPs) e as reservas legais ${ }^{3}$.

A tutela diferenciada dessas áreas ocorre em razão da existência de determinados bens ambientais cuja preservação é imprescindível à boa qualidade daquele ecossistema local. "São áreas situadas onde a vegetação é essencial à manutenção de um meio ambiente sadio" (ALMEIDA, W., 2006, p. 81), como matas ciliares, em volta de lagos, lagoas, reservatórios d'água, de nascentes, nos topos e encostas de morros, nas restingas, etc.

Sobre o amparo legal destas regiões, Machado comenta:

A vegetação, nativa ou não, e a própria área são objeto de preservação não só por si mesmas, mas pelas suas funções protetoras das águas, do solo, da biodiversidade [...], da paisagem e do bem-estar humano. A área de preservação permanente APP é um favor da lei, é um ato de inteligência social e é de fácil adaptação às condições ambientais (MACHADO, 2005, p. 719).

A seca que expulsa as pessoas e os desmoronamentos que matam têm como uma de suas causas o corte da vegetação de preservação permanente (MACHADO, 2005, p. 722).

As APPs estão conceituadas, como mencionado anteriormente, no art. 1ํ, $\S 2^{\circ}{ }^{\circ}, I I$, do Código Florestal e são áreas protegidas nos termos dos arts. 2o e 3ำ do Código Florestal, cobertas ou não por vegetação nativa. A diferença entre elas é que as inscritas no art. $2^{\circ}$ são caracterizadas como legais, imperativas, consideradas pelo só efeito da lei, e só por lei poderão ser alteradas ou suprimidas parcial ou totalmente; já as insertas no art. 3o, constituem APPs quando assim declaradas por ato de Poder Público, também conhecidas como administrativas (ALM EIDA, W., 2006, p. 81).

3 Machado aponta uma diferença importante entre estes dois institutos: "Diferenciam-se no que concerne ao domínio, pois a Reserva Legal Florestal somente incide sobre o domínio privado, sendo que as Áreas de Preservação Permanente incidem sobre o domínio privado e domínio público." (M ACHADO, 2005, p. 739). 
No primeiro caso, as áreas são tuteladas por sua própria situação, vegetação e localidade, que demandam a proteção - são estas APPs o objeto da presente pesquisa -, enquanto que no segundo, a tutela é relacionada com a finalidade para as quais foram protegidas (MACHADO, 2005, p. 720).

A preservação das APPs é de suma importância à boa qualidade do meio ambiente e, consequentemente, à sadia qualidade de vida, valores totalmente dependentes e proporcionais à observância e obediência aos parâmetros estipulados para preservação das mesmas.

A princípio, o ordenamento jurídico "proibiu utilização que alterasse as características e os atributos que deram fundamento à especial proteção" (ANTUNES, 2005, p. 528). Contudo, observou-se a impossibilidade de manter o homem totalmente afastado das APPs, e constataram-se ocupações irregulares sem qualquer respeito às matas nativas a serem mantidas. Aliás, tal fato tem motivo em razão das dificuldades encontradas para praticar as limitações estabelecidas no Código Florestal.

E, pensando nisso, que o CONAM A - Conselho Nacional do Meio Ambiente - editou algumas resoluções visando elucidar as dúvidas percebidas em casos concretos, fortalecer os limites de APPs a serem observados e, definir, com mais propriedade, os casos, já previstos em lei, em que é aceitável intervenção em APPs, mas de forma a manter a conservação destas.

A Resolução do CONAMA no 369 de 28.03.2006 "dispõe sobre os casos excepcionais, de utilidade pública, interesse social ou baixo impacto ambiental, que possibilitam a intervenção ou supressão de vegetação em Área de Preservação Permanente - APP", e visa normatizar situações cuja previsão legal é genérica, e, que na realidade se fizeram presentes e carentes de regulamentação mais específica.

Ao implementar um importante aspecto da função social da propriedade proteção ambiental das águas - as Resoluções do CONAMA mencionadas não inovam o ordenamento legal, apenas conferem eficácia a um dispositivo do Código Florestal que, à míngua de regulamentação, não poderia ser aplicado (FIGUEIREDO, 2005, p. 232).

A presente resolução encontra respaldo no Código Florestal, em seu art. 1ํㅡ, §2ำ, incisos IV, alínea " $c$ ", e V, alínea " $c$ ", em que atribui ao CONAMA a competência para prever, em 
resolução, os casos de "obras, planos, atividades ou projetos" de utilidade pública e de interesse social e, no art. 4ํ que prevê a exceção à regra, nos casos de utilidade pública e interesse social, quando preenchidos os requisitos, ou a supressão eventual e de baixo impacto ambiental quando o órgão ambiental competente autorizar.

Esta resolução, além de melhorar as exigências do Ordenamento Florestal, é importante instrumento para direcionar a atuação do Poder Público, quanto ao seu poder de fiscalização e liberação do uso destas regiões.

Por essas e outras razões, a intervenção em APPs, "caracterizadas pela intocabilidade e vedação de uso econômico direto" ${ }^{4}$, é abordada com cautela e permitida em alguns casos.

\section{Políticas públicas ambientais}

Assim, tendo em vista o dever de tutela dos bens ambientais, o papel do Estado na defesa ambiental é de suma importância. Como é sabido, o Estado atua traçando planos de ações, pelas chamadas políticas públicas, que abrange etapas educativas, de coordenação e de realização. E assim o é com a questão ambiental e seus bens.

Afinal, não pode o Estado acreditar que a simples existência de leis protetoras do meio ambiente irá solver os complexos problemas ambientais. É preciso que o debate ambientalista se concretize por meio da implementação do direito ambiental "a partir de posições concretas a serem assumidas pelos atores a exercerem a ação participativa e comunicativa que a realidade exige" (DUARTE, 2003, p. 226).

Não se pode olvidar que os problemas sócio-econômicos devem integrar o planejamento. Afinal, a idéia de ordenamento do território considerando-o apenas como espaço físico já está ultrapassada por saber que as mudanças e alterações do meio ambiente são constantes devido às atividades humanas, o que implica no envolvimento das atividades sociais e econômicas.

Para Almeida et al. (2004, p. 37), a implantação de políticas ambientais no Brasil, apesar dos esforços institucionais, não tem se efetivado plenamente pela "forma como a questão ambiental vem sendo tratada" em razão da prevalência de interesses econômicos em contraposição com a gestão ambiental.

4 Introdução da Resolução CONAMA n. 369/2006. 
Boa parte das áreas a serem protegidas nem ao menos foram demarcadas. 0 sistema de combate à degradação e à poluição ambientais tem-se mostrado ineficiente. [...] 0 mais 'perfeito' plano em nada resolverá as questões ambientais, se o espaço não for entendido como uma instância social e não como mero apoio das atividades humanas. 0 espaço físico é o reflexo não apenas dos processos naturais, como também das contradições da sociedade, na medida em que são os interesses sócio-econômicos os determinantes das formas de apropriação e exploração do espaço (ALMEIDA et al., 2004, p. 37)

Sobre as áreas de preservação permanente situadas em espaços urbanos devem incidir políticas públicas que garantam a efetividade da proteção especial atribuída por lei a estes espaços e que delimitem como será o uso destas áreas.

No arcabouço jurídico brasileiro, encontram-se diversas normas importantes para auxiliar e instrumentalizar a elaboração de políticas públicas ambientais mais eficientes e com poder concreto de viabilizar a boa gestão da vida urbana, como caso da Lei 10.257/2001, Estatuto da Cidade.

Além de contemplar pela primeira vez em norma infraconstitucional o termo planejamento de cidades, esta lei estabelece diretrizes gerais da política urbana, prevendo os instrumentos para o alcance desta, tratando da gestão democrática da cidade e institui 0 plano diretor, regulamentando, assim, os arts. 182 e 183 da Lei Maior.

Importante frisar outros instrumentos legais que auxiliam a ordem urbanística, como a Lei Orgânica, considerada a Constituição do Município; a Lei de Diretrizes Orçamentárias; o Código de Obras; o Código de Posturas; a Lei de Parcelamento do Solo.

Esta última pretende sistematizar, no plano nacional, o processo de expansão urbana, que deverá ocorrer mediante loteamento ou desmembramento (art. 2ํㅡ, Lei noㅡ $6.766 / 79)$.

José Afonso da Silva conceitua parcelamento do solo urbano como "o processo de urbanificação de uma gleba, mediante sua divisão ou redivisão em parcelas destinadas ao exercício das funções elementares urbanísticas" (SILVA apud M UKAI, 2002, p. 295).

Silva destaca a importância da fiscalização pela comunidade do modo como os loteamentos são aprovados, a fixação de equipamentos públicos, de áreas verdes, o traçado da malha viária, do saneamento básico, afinal, a qualidade e 0 atendimento as regras urbanísticas e ambientais afetará a qualidade de vida de toda a população: 
Há um inegável interesse público para os cidadãos em fiscalizar a qualidade do loteamento. A ausência de condições sanitárias e a ação dos elementos poluentes terão conseqüências não só sobre os compradores de lotes, mas sobre toda a comunidade (SILVA, J. A., 2004, p. 416).

\section{Irregularidades urbanas e problemas ambientais}

Entretanto, não é essa a situação apresentada nas urbes brasileiras, em que se constata o desatendimento à Lei Maior e à legislação pátria. Como é o caso de M unicípios que não elaboram planejamento e controle adequado do uso, parcelamento e ocupação do solo urbano ou atuam de forma deficitária.

E, por conta disto, permitem ou deixam passar por aprovações loteamentos ou desmembramentos eivados de irregularidades, em desacordo, principalmente, à defesa ambiental e a outros direitos imprescindíveis, como à dignidade da pessoa humana, à moradia.

Muito disso se deve ao acelerado processo de urbanização, que aporta para as cidades aspirações sociais de quem vem nela habitar e suas carências como cidadãos, sociais e financeiras, criando um quadro de urbanização da pobreza. Ademais, cria-se uma situação em que esta parcela populacional pressiona o Estado para que atenda as demandas e implante infra-estrutura social, como educação, saúde, transporte, moradia, limpeza, segurança.

O surto de urbanização sem o correspondente crescimento econômico, gerando, com isso, centros urbanos dualistas: de um lado, a cidade formal, expressas nas escrituras públicas e nas matrículas dos registros de imóveis, e de outro, a cidade informal, visível pela dura imagem das palafitas, vilas e favelas (LOTTI, 2008).

Na visão de Genz, este processo representa:

Um contínuo aumento de assentamentos informais e precários, destituídos de mínimas condições de habitabilidade, em que persiste a carência de infra-estrutura básica para quem se submete a esta aventura. 0 resultado deste tipo de ocupação é a precariedade das condições de vida para todos, e a constante degradação ambiental (GENZ, 2008).

O Estado não consegue controlar a aceleração urbana, caracterizada pela expansão desordenada e descontínua e, em regra sem qualquer organização ou planejamento. E 
muito menos, fiscalizar ou corrigir os defeitos nascidos com a acelerada urbanização (Genz, 2008).

Assim, com a alta pressão demográfica e a inabilidade do Poder Público para sistematizar a expansão das cidades, a ocupação do solo ocorre, com freqüência, em áreas protegidas ambientalmente, advindo daí a relação entre destruição de florestas e demais vegetações e a pobreza.

Diversos são os fatores que explicam a ocupação em APPs. Dentre eles, pode-se citar a inexistência ou mínima conscientização da população acerca da importância ambiental e da preservação desses espaços, devido à falta de educação ambiental; o conhecimento pela população sobre legislação ambiental prevendo a intocabilidade das APPs, mas o contínuo desrespeito às leis, devido à falta de sanções ou repreensões significativas que inibam novas práticas ${ }^{5}$; ou ainda o desconhecimento das leis ambientais, 0 que demanda a socialização, a democratização do repertório jurídico brasileiro, a chamada “popularização da questão ambiental” (DUARTE, 2003, p. 190).

$E$, por não contar com "instrumentos capazes de cumprir com seus deveres plena e igualitariamente, como garantir a todos o direito à moradia, quem, na maioria das vezes, suporta as conseqüências do desatendimento do Estado são as camadas economicamente menos favorecidas da população" (M ENECHINO; PROCÓPIO; VIANNA, 2007).

Aliás, soma-se a isto a forte especulação imobiliária, em que interesses privados são sobrepostos a interesses ambientais e sociais; e o descaso do Poder Público a estas situações.

0 ordenamento urbanístico ficou ao sabor de improvisações e de pressões locais. Constatava-se a tensão entre 0 interesse privado e o interesse público, isto é, a posição do loteador e os interesses atuais e futuros da humanidade (SILVA, J. A., 2004, p. 401).

As ocupações irregulares em APPs podem ser constatadas em casos de loteamentos residenciais, clandestinos ou não, para a população de baixa renda - objeto do presente estudo -, para pessoas com alto poder aquisitivo, como condomínios fechados e de veraneio; e ainda assentamentos, favelas ou habitações precárias fruto de invasão da área.

5 A esse respeito, Duarte adverte que "o tratamento desigual dado àqueles que de algum modo infringem a legislação ambiental, leva muitas vezes a um descrédito da ação estatal" (DUARTE, 2003, p. 187). 
Sem qualquer planejamento, moradias são edificadas ao redor de nascentes, marginais a cursos d'água, em encostas de morro, dentre outras, sem haver preocupação em analisar a possibilidade e viabilidade de ali utilizar (MENECHINO; PROCÓPIO; VIANNA, 2007).

Para serem adequadas, tais políticas deveriam considerar a implementação de legislação ambiental, aparelhar órgãos ambientais para que cumpram com o plano diretor, entre outras leis, e atuem utilizando os instrumentos políticos fornecidos no Estatuto da Cidade, por exemplo.

Um possível caminho apontado por Genz para a questão, seria o Poder Público direcionar sua atenção à racionalização e organização dos espaços físicos e demográficos, objetivando planejar o desenvolvimento da cidade como forma de garantir à população menos privilegiada o direito à qualidade de vida, à moradia digna, à salubridade ambiental (GENZ, 2008).

Entretanto, esta racionalização e organização se mostram difícil de concretizar na prática, pois, as políticas públicas, que normatizam a relação de apropriação do espaço pelo poder, configuram palcos de relações conflituosas entre interesses do Estado, de agentes privados, - como empreendedores imobiliários, loteadores, empresas da construção civil, empreiteiras, proprietários de terras -, e a população em geral, - moradores de bairros, movimentos populares, organizações não-governamentais, associações e sindicatos (MENECHINO; PROCÓPIO; VIANNA, 2007).

As políticas que seriam responsáveis pela equidade social têm ficado reiteradamente em segundo plano face ao interesse do capital privado, que vezes se apropria do território para alojar suas redes de interesse. (MENECHINO; PROCÓPIO; VIANNA, 2007).

No plano da distribuição dos espaços, o capitalismo não sustentável caracteriza-se pela simultânea degradação do meio ambiente e pelo aprofundamento da desigualdade econômica (FIGUEIREDO, 2005, p. 128).

Comprova-se esta constatação em loteamentos irregulares ${ }^{6}$, destinados à população de baixa renda, efetivados em áreas de preservação permanente, muitas vezes

6 Loteamento Irregular é aquele que possui algum tipo de registro no M unicípio. 0 responsável pode ter feito uma consulta prévia ou ter dado entrada com parte da documentação, mas não chegou a aprovar o projeto. Também é considerado irregular o loteamento que tem projeto aprovado, mas o loteador deixou 
com a anuência do Poder Público, que posteriormente se consolidam em razão da incapacidade do Estado em resolver a problemática habitacional.

Transcende 0 interesse particular do Município a estruturação básica de um loteamento. Apontar as mesmas condições mínimas de sanidade para todas as comunidades da Nação é tarefa que se fazia improrrogável, pois, do contrário, propiciavam-se num mesmo país pontos de convulsão social e locais onde não se mora, não se habita mas se sobrevive a duras penas. De outro lado, a continuação da manifesta diferença das exigências urbanísticas para lotear concorria para aumentar as desigualdades regionais e estimulava a concorrência entre cidades, possibilitando que poderosos loteadores só investissem onde menos se exigisse (SILVA, J. A., 2004, p. 401).

Afinal, devido às diversas restrições impostas para garantir a função ambiental das APPs, criou-se um conceito entre a população de que o exercício do direito de propriedade ali será limitado. 0 que explica, em muitos casos, a não valorização da área e a baixa procura pelo setor imobiliário.

Há quem sustente que a vedação legal de edificar pode eventualmente acarretar a redução do valor comercial de terrenos situados em áreas de mananciais. Ao atingir um certo patamar, a vedação legal provoca um desequilíbrio no valor de mercado do bem imóvel, reduzindo-o a ponto de não mais justificar a sua guarda. Ocorre, aqui, o chamado esvaziamento do conteúdo econômico da propriedade. Nesse caso, os proprietários simplesmente abandonam suas propriedades, deixando muitas vezes de pagar o imposto predial. Em outros casos, buscam a sorte em ações indenizatórias propostas em face da Fazenda Pública. Numa ou noutra situação, ao arrepio do princípio da função social da propriedade (FIGUEIREDO, 2005, p. 244).

E, é neste aspecto que se depreende o liame entre a procura de loteadoras e outros agentes privados no interesse por APPs para fins de loteamentos destinados à população economicamente menos favorecida. Esta parcela populacional é quem depende mais das políticas e auxílio do Poder Público, devido as suas carências e, é quem mais exerce a pressão habitacional nas cidades. Por isso, muitos são os loteamentos feitos irregularmente em APPs, pelo custo ser menor, e aprovados pelo Estado.

de executar as obras previstas ou não registrou o projeto junto ao Registro de Imóveis. 0 resultado disto é uma área com infra-estrutura incompleta ou sem as mínimas condições para ser habitada. Loteamento Clandestino é aquele executado sem qualquer tipo de consulta à Prefeitura e onde o loteador não respeita nenhuma norma urbanística. Não há garantia, sequer, de que o loteador é o proprietário da área. Disponível em: http://www.rigepar.com.br/estrutura.asp?src=novidades.asp\&id=menu=0. Acesso em: 11 maio 2008. 
Sob o aspecto econômico e imobiliário, a ocupação humana de áreas de mananciais decorre da pressão demográfica por parte de uma larga faixa da população economicamente menos favorecida sobre imóveis localizados em regiões onde não ocorreu uma valorização imobiliária suficiente para motivar a proteção do patrimônio privado pelos interessados, fator que se alia à omissão do Poder Público no seu dever de zelar pela incolumidade dessas áreas (FIGUEIREDO, 2005, p. 244).

0 certo é que, por mais que as ocupações habitacionais em APPs tenham sido aprovadas, os licenciamentos obtidos não são confiáveis, e os empreendimentos são feitos em desacordo às restrições ambientais (M ENECHINO; PROCÓPIO; VIANNA, 2007).

É preciso compreender que o dano ambiental provoca, também, esse dano social, representado pelo tempo durante 0 qual a coletividade fica privada da fruição do bem ou recurso ambiental afetado pela atividade danosa e do benefício que ele proporcionava ao equilíbrio ecológico (SAM PAIO apud STEIGLEDER, 2004, p. 168).

A intervenção nestes espaços, quando não é feita sob os ditames legais com a devida autorização e preenchidos os requisitos, ocorre irregularmente, o que contribui e potencializa os problemas sócio-ambientais.

Assim, as ocupações em APPs, por estarem na ilegalidade, carecem de políticas públicas destinadas a suprir as necessidades básicas dos moradores e padecem de problemas estruturais, por exemplo, a péssima acessibilidade, inexistentes ou escassas condições de salubridade, de infra-estrutura básica e de adequados equipamentos públicos, em que faltam postos de saúde, escolas, entre outros.

Outrossim, desrespeita-se diretamente preceitos basilares previstos na Constituição Federal, como o direito à dignidade da pessoa humana, da sadia qualidade de vida, vez que estas ocupações caracterizam verdadeiras áreas de risco, sem condições de salubridade, de habitabilidade - em que residências são repletas de infiltrações, umidade excessiva e problemas estruturais, situadas em locais com risco de desabamento.

Ademais, quem adquire lotes ou casas em loteamentos irregulares, ou está diretamente relacionado às ocupações irregulares em APP, sofre ainda as seguintes conseqüências ${ }^{7}$ : 1) não poderá registrá-lo ou mesmo regularizá-lo. Vai ter apenas a posse, mas não será dono daquilo que pagou; 2) ficará sempre na incerteza se vai poder

7 Dados extraídos do site da Prefeitura Municipal de Porto Alegre - RS. Disponível em: «ttp://www2.portoalegre.rs.gov.br/pgm/default.php?reg=5\&p_secao=29>. Acesso em: 17 jun. 2008. 
permanecer no local; 3) a venda pode ter sido feita por alguém que detém a posse da área, mas não é o proprietário. Neste caso o verdadeiro dono poderá entrar com uma ação pedindo reintegração de posse e ser determinada a desocupação da área; 4) o comprador ficará na dependência da "boa-vontade" do mau loteador, muitas vezes tendo que morar num local sem uma infra-estrutura básica, como água potável, energia elétrica, iluminação pública e redes de esgoto; 5) terá dificuldades de acesso, pois na maioria das vezes as ruas são abertas com largura inadequada, impedindo a circulação do transporte coletivo; 6) não contará com praça, escola ou posto de saúde próximos de sua casa, pois o mau loteador não destina uma parte da área, como prevê o Plano Diretor, para colocação destes equipamentos; 7) não conseguirá financiamento junto aos bancos ou outras instituições financeiras para construir ou reformar sua casa, porque não terá como apresentar a documentação exigida; e, 8) não terá como demandar melhorias para o local via Orçamento Participativo.

A situação é assim explicada por Menechino, Procópio e Vianna (2007):

A conseqüência deste tipo de política é a segregação da população de baixa renda em sub-habitações edificadas em locais de preservação ambiental, cuja função é justamente proteger recursos naturais como o solo e a água e ser um refúgio para a biodiversidade. Esses locais, por suas características estruturais, são inviáveis para a instalação de vias de circulação e de equipamentos urbanos. Criam-se áreas isoladas, carentes dos serviços essenciais como saneamento básico, água tratada, galerias de águas pluviais. Tornam-se verdadeiros labirintos de acesso único, favorecendo inclusive a criminalidade.

A idéia de sustentabilidade das cidades implica na satisfação concreta dos direitos à moradia, ao saneamento, a vias de circulação, segurança, democracia, educação e serviços públicos adequados e infra-estrutura urbana para atender às demandas sociais. Não há que se cogitar a sustentabilidade das cidades sem o provimento adequado destes equipamentos públicos a to da população, vez que promove a exclusão social e fere o princípio da isonomia.

Somente será possível pensar em cidades sustentáveis quando houver um movimento no sentido de solucionar os problemas ambientais, cumprindo os passivos ambientais ${ }^{8}$, evitar os próximos, e quando forem elaboradas políticas palpáveis, em que haja ação real e efetiva do Estado para cumpri-las.

8 Em definição extraída do Dicionário Brasileiro de Ciências Ambientais, Vânesca Buzelato Prestes explica que a idéia de passivo ambiental vem das ciências econômicas e implica em "valor monetário, composto 
Nas ocupações irregulares em APPs, em que a proteção dada àquelas áreas foi rompida, as funções ambientais que se visavam proteger provavelmente estão minimizadas ou ausentes, caracterizando danos não somente ecológicos, mas sociais a quem habita e à coletividade. Do mesmo modo, que a manutenção de tais situações fazem as cidades caminharem na direção contrária à sustentabilidade.

Por isso, a necessidade de amenizar as problemáticas apresentadas. E, um instrumento jurídico que guarda simetria como possível solução é a regularização fundiária, conforme previsão legal.

Não podemos mais 'fazer de conta' que a irregularidade urbana não é um problema ambiental ou que é somente deficiência do poder de polícia. Este enfrentamento exige conhecimento da realidade, engajamento das comunidades trabalhadas, e, sobretudo, atuação interdisciplinar e inter-órgãos, de modo que os mesmos problemas sejam vistos com outro olhar. Um olhar que responsabiliza e compromete a todos os setores da Administração Pública e que possibilite o nascer de estratégias e soluções a partir dos casos concretos, tendo como fio condutor a melhoria das condições urbano-ambientais das áreas trabalhadas e a dignidade da pessoa humana, gerando a tão almejada e propagada inclusão social (PRESTES, 2007, p. 410).

\section{Regularização fundiária urbana}

Quando as intervenções em APPs ocorrem ilegalmente, os bens que se visavam proteger ficam expostos à vulnerabilidade das atividades humanas e as ocupações nascem padecidas de irregularidades, resultando em danos ao meio ambiente - à qualidade da água, do solo, das vegetações, ao fluxo gênico.

A ilegalidade gera, ainda, o não fornecimento de equipamentos públicos, infraestrutura urbana e serviços sociais essenciais para suprir as necessidades básicas humanas, comprometendo 0 atendimento a direitos constitucionais.

Assim, os loteamentos irregulares têm íntima relação com a forma como cada cidade cumpre com as leis e pratica suas políticas públicas. E tendo em vista que tais

basicamente de três conjuntos de itens: o primeiro, composto das multas, dívidas, ações jurídicas (existentes ou possíveis), taxas e impostos pagos devidos à inobservância de requisitos legais; o segundo, composto dos custos de implantação de procedimentos e tecnologias que possibilitem o atendimento às não conformidades; o terceiro, dos dispêndios necessários à recuperação de área degradada e indenização à população afetada. Importante notar que este conceito embute os custos citados acima mesmo que eles não sejam ainda conhecidos; e, pesquisadores estudam como incluir no passivo ambiental os riscos existentes, isto é, não apenas o que já ocorreu, mas também o que poderá ocorrer" (PRESTES, 2007, p. 401). 
ocupações não são benéficas para as cidades, os danos percebidos nestas áreas devem ser resolvidos o mais rápido possível a fim de garantir a defesa ambiental e assegurar direito fundamentais à população, e inclusive evitar irregularidades administrativas, quando se constata a atuação ou omissão do Poder Público de forma contrária às legislações.

A garantia a estes direitos é que orientam a adoção pelo Poder Público de quais medidas seria a mais viável para cada caso, dentro dos instrumentos previstos em legislação, como a regularização fundiária urbana, por exemplo.

Afinal, a transferência dessas ocupações, para que as APPs fossem efetivamente protegidas, em cumprimento ao Código Florestal, para outros locais é muitas vezes de difícil concretização. Pois, há que se considerar determinados aspectos sociais e culturais inerentes àquela situação, bem como direitos já consolidados, como a liberdade de cada indivíduo, para escolher habitar naquele bairro e não em outro, a vontade de permanecer naquelas redondezas, os costumes similares daquela região urbana que pode ser diferente dos de outra.

É nítida a impossibilidade de remover essas ocupações e simplesmente distribuir a pressão habitacional para outras localidades urbanas. Mesmo que a ocupação fosse totalmente retirada, as conseqüências das ocupações irregulares permaneceriam visíveis, como contaminação hídrica, por despejo de esgoto, erosão do solo e diminuição da área verde.

Não seria ambientalmente mais adequado identificar o que ainda é possível proteger e, no restante, investir em urbanização (tratamento de esgoto, medidas para conter impermeabilização, controle das edificações etc.) para minimizar os impactos decorrentes da ocupação? (PRESTES, 2006, p. 44).

Deve-se buscar uma harmonia entre as atividades humanas e a proteção ambiental; pois o homem tem o direito, e o Estado o dever de garantir a dignidade humana. Por outro lado, para ter vida digna, o ser humano necessita do meio ambiente adequado, em que a qualidade dos bens ambientais se mostre adequada e compatível com a harmonia almejada.

Numa primeira análise do caso poderíamos entender que estaria configurada uma ocupação ilegal de área incontestável função ambiental, que imporia a imediata e incondicional desocupação da área. Desenvolvendo uma análise mais acurada do problema, [...] seria necessário não propor uma imediata retirada dos 'sem-teto', mas aquilatar as circunstâncias concretas da área protegida, a fim de ser verificada, 
por exemplo, se persistem as características que tornaram tais áreas como de preservação ambiental ou se a mesma já foi descaracterizada a tal ponto, por uma massiva urbanização, que não mais se justifica a sua função ambiental, ou se ela nunca chegou a cumprir a função originalmente prevista, devendo, neste último caso, ser analisada a possibilidade de implantação de programas de regularização fundiária (DUARTE, 2003, p. 196-197).

A regularização fundiária sustentável apresenta-se como medida de harmonização entre a relação homem e meio ambiente "amenizando os efeitos destrutivos destas ocupações, seja a degradação ambiental, a irregularidade administrativa, a ilegalidade da própria ocupação e os problemas sociais" (M ENECHINO; PROCÓPIO; VIANNA, 2007).

O estrago já feito não será potencializado e os efeitos causados poderão ser mitigados [...] formando certo nível de consciência ambiental acerca do modo com que a interferência antrópica sem controle prejudica a qualidade de vida de todos, alterando a própria existência do homem e do meio em que vive (MENECHINO, PROCÓPIO; VIANNA, 2007).

Os autores complementam que a metodologia será através da inibição de assoreamento de córregos e nascentes, de eliminação irregular de resíduos, de realização de obras necessárias ao ambiente urbanístico (instalação de galerias e redes de esgoto adequadas, escoamento adequado de águas pluviais, diminuição da impermeabilização do solo urbano).

Betânia de Morais Alfonsin elucidativamente conceitua a regularização fundiária:

0 processo de intervenção pública, sob os aspectos jurídicos, físico, social que objetiva legalizar a permanência de populações moradoras de áreas ocupadas em desconformidade com a lei para fins de habitação, implicando acessoriamente melhorias no ambiente urbano do assentamento, no resgate da cidadania e da qualidade de vida da população beneficiada (ALFONSIN apud STEIGLEDER, 2004, p. $61)$.

Assim, projetos de regularização fundiária, considerados como uma forma de política pública ${ }^{9}$ destinados a garantir moradia com sustentabilidade, mostram-se plausíveis e devem impactar positivamente na relação moradores versus natureza, com a manutenção

9 Vânesca Buzelato Prestes qualifica a regularização fundiária sustentável como política pública em razão de que a "dimensão da irregularidade urbana é de tal monta que deixa de ser um problema individual para ser um problema difuso, que afeta toda a coletividade" (PRESTES, 2007, p. 402). 
dos ocupantes em suas moradias e a remoção daqueles cuja habitação oferecia riscos, investimentos em serviços públicos e melhoria da área em geral.

Para Alfonsin, o resultado esperado após a regularização fundiária é que a relação da comunidade, pós-intervenção, "seja menos predatória com os recursos naturais existentes na região, até pelos investimentos realizados em termos de saneamento e infraestruturação [...] o que previne a poluição ambiental e a contaminação dos solos, córregos e lençóis freáticos" (ALFONSIN apud DUARTE, 2003, p. 197).

Os processos e procedimentos de regularização fundiária sustentável encontra justificativa dentro do pensamento sobre a reforma urbana, de modo a inserir 0 cidadão dentro da legalidade urbanística e jurídica e, bem assim, regular uma imensa camada da cidade que se encontra hoje alheia ao processo de crescimento oficial da cidade. (AFONSO; M INEIRO, 2007, p. 598).

Neste particular, a regularização fundiária mostra-se como um passivo ambiental, que o Poder Público, em débito com suas obrigações, deve à população.

0 art. 2ำ da Lei 10.257/2001 prevê a regularização fundiária como um instituto jurídico e político. E a Resolução do CONAM A nํ 369/2006, também a prevê em seu art. 9․ .

A regularização fundiária sustentável prevista na resolução do CONAM A aplica-se a áreas que estiverem previamente ocupadas. $E$, sua incidência ocorre somente nos casos, determinados no art. 9o da referida Resolução, que preencherem os requisitos inscritos nesta norma, por exemplo, ser predominantemente de baixa renda e residenciais, possuir três itens implantados de infra-estrutura urbana (como captação de águas pluviais, malha viária, rede de distribuição de energia, etc), dentre outros.

Ressalte-se que as APPs remanescentes daquela ocupação devem restar intocadas, sem qualquer intervenção ou supressão (art. 9으, §§ 4ำ e 5으). Tal dispositivo é porque nestas hipóteses, as características que definem estas áreas como de preservação permanente ainda se fazem presentes. Prestes pondera acerca da importância de gravar as APPs remanescentes:

Com este processo as áreas objeto da regularização passam a integrar a cidade formal, ou seja, sendo passíveis das medidas de poder de polícia e de controle edilício como existe em toda a cidade. Assim, se forem ocupadas estarão sujeitas às medidas jurídicas pertinentes (demolição, reintegração de posse, Ação Civil Pública etc.) (PRESTES, 2007, p. 408). 
E, nas áreas identificadas no plano como de risco de inundações, corrida de lama, de movimentos de massa rochosa, entre outras consideradas de risco, é vedada a regularização fundiária de ocupações, devido à instabilidade da região e à grande possibilidade de ocorrência de desastres naturais.

Contudo, como bem pontua Genz, é importante que o Poder Público, de forma complementar aos projetos de regularização fundiária, crie estratégias e aplique-as para prevenir novas ocupações irregulares, por meio de ampliação da oferta de moradias, por exemplo; de forma a evitar futuros casos. (GENZ, 2008).

Por fim, Jacqueline Severo da Silva partilha do mesmo entendimento:

Não basta uma política de regularização fundiária sem a existência de políticas de produção de habitação de interesse social, motivo pelo qual não seria imposto limite ao processo de produção de irregularidade. Da mesma forma, de nada adianta atender as necessidades sociais de moradia sem o reconhecimento da 'ilegalidade' já produzida. Trata-se, portanto, de reconhecer o direito ao acesso a terra à população de baixa renda, moradora de áreas de ocupação, bem como, 0 seu 'direito à cidade' (SILVA, J. S., 2001).

$\mathrm{Na}$ cidade de Londrina, têm-se alguns exemplos de loteamentos que padecem de irregularidades, como o Residencial José Lázaro Gouveia, Jardim Neman Sahyun, Jardim Itapoã, Jardim Versalhes e o Jardim Vale Verde, em que se constata a intervenção em APPs e que padecem de todos os problemas apontados no presente trabalho.

No Jardim Vale Verde, fala-se em mais de cem (100) casas construídas em APPs, em cima de nascentes, oferecendo riscos à saúde e segurança da população.

Em alguns pontos deste loteamento observa-se a inexistência de coleta de lixo adequada e regular; a inexistência de calçadas e vias de acesso; escassa arborização das vias; redes de água, esgoto e luz instaladas de forma precária ou inexistente. Isso sem mencionar a inexistente ou deficitária prestação de serviços de educação, creches, postos de saúde, transporte, o que deixa a população daquela região totalmente desamparada.

0 ideal seria retirar toda a ocupação das áreas de preservação permanente e alocálas em local apropriado e que o Estado possa fornecer condições essenciais para viver. Há alguns entendimentos jurisprudenciais neste sentido, a saber:

Ementa: Parcelamento do solo urbano - Dano ambiental - Caracterização Loteamento irregular - Ocupação desordenada da área - Inexistência de 
planejamento urbanístico e ambiental - Poluição decorrente da conduta dos ocupantes - Recomposição da área de preservação permanente ao estado primitivo que se impõe - (MINAS GERAIS, 2004).

Contudo, e como já explicitado, muitas vezes tal medida é inviável.

Por todo o exposto, a regularização fundiária apresenta-se como instrumento de política pública de suma importância para os municípios brasileiros na busca pela solução de problemas urbano-ambientais, como o caso de ocupações irregulares em APPs, e para garantir a sustentabilidade das cidades.

\section{Conclusão}

Com o presente artigo buscou-se analisar a constante dificuldade em cumprir os parâmetros nas metragens estabelecidas em leis e, por conseqüência, em controlar a intervenção e ocupações de forma irregular em APPs, como o caso de loteamentos destinados à população de baixa renda, em desatenção a diversas normas, criando verdadeiros adensamentos populacionais irregulares.

Como conseqüência das ocupações irregulares, surgem problemas graves enfrentados pelos moradores da área, que vêem seus direitos fundamentais ignorados, comprometendo a inclusão destes ao desenvolvimento da cidade. $E$ ainda, as ocupações irregulares prejudicam a cidade como um todo, pois geram danos ambientais, muitas vezes irreparáveis, lesionando bens ambientais que pertencem a toda coletividade de forma indistinta.

Assim, os loteamentos irregulares têm íntima relação com a forma como cada cidade cumpre com as leis e pratica suas políticas públicas. E tendo em vista o malefício causado por estas ocupações para as cidades, os danos percebidos nestas áreas devem ser resolvidos o mais rápido possível a fim de garantir a defesa ambiental e assegurar direito fundamentais à população.

Por isso, a regularização fundiária apresenta-se como um passivo ambiental, que 0 Estado deve cumprir para amenizar os problemas sentidos em loteamentos irregulares, de forma a conciliar um nível de proteção às APPs - que garanta a função ambiental pela qual foi tutelada -, e não ter de retirar as pessoas ocupantes daquela região, pois tal medida seria de difícil cumprimento e, em determinados casos, de resistência pela comunidade. 
E, por fim, é através da regularização fundiária que se buscará propiciar benefícios sócio-ambientais, fornecendo serviços públicos eficientes, como educação, saúde, transporte; áreas de lazer, enfim, condições dignas de habitabilidade.

Afinal, a sustentabilidade das cidades e 0 atendimento a direitos fundamentais estão intimamente relacionados com a solução para os problemas ocasionados e decorrentes das ocupações irregulares.

\section{Referências}

AFONSO, M iguel Reis; MINEIRO, Edílson Henrique. Áreas urbanas consolidadas e as propostas de regularização fundiária. In: BENJAM IN, Antonio Herman; LECEY, Eladio;

ALM EIDA, Josimar Ribeiro de et al. Política e Planejamento Ambiental. 3. ed. Rio de Janeiro: Thex Ed., 2004.

ALM EIDA, Washington Carlos de. Direito de propriedade: Limites ambientais no Código Civil. Barueri: Manole, 2006.

ANTUNES, Paulo de Bessa. Direito ambiental. 8. ed. rev. ampl. e atual. Rio de Janeiro: Lumen Júris, 2005.

CAPPELLI, Silvia (Org.). Congresso Internacional de Direito Ambiental. M eio ambiente e acesso a Justiça: flora, reserva legal e APP. 1. v. São Paulo: Imprensa Oficial do Estado de São Paulo, 2007.

DUARTE, Marise Costa de Souza. M eio ambiente sadio: direito fundamental em crise. Curitiba: Juruá, 2003.

FERREIRA, Adyr Sebastião. Danos ambientais causados por Hidrelétricas. Brasília: OAB Editora, 2006.

FIGUEIREDO, Guilherme José Purvin de. A Propriedade no Direito Ambiental. 2. ed. rev. e ampl. Rio de Janeiro: Esplanada, 2005.

GENZ, Karin Sohne. 0 plano diretor como instrumento de política urbana. Porto Alegre. Disponível em: বttp://www.mp.rs.gov.br/urbanistico/doutrina/id492.htm>. Acesso em: 04 maio 2008.

LOTTI, Armando Antônio. Instrumentos de ordenamento territorial para o desenvolvimento urbano e regularização de ocupações. Porto Alegre. Disponível em: বhttp://www.mp.rs.gov.br/urbanistico/doutrina/id397.htm>. Acesso em: 07 maio. 2008.

M ACHADO, Paulo Affonso Leme. Estudos de Direito Ambiental. São Paulo: M alheiros, 1994. 
. Direito ambiental brasileiro. 13. ed. rev. ampl. e atual. São Paulo: M alheiros Editores, 2005.

M ARCHESAN, Ana Maria Moreira. Áreas de "degradação permanente", escassez e riscos. In: BENJAM IN, Antônio Herman V.; M ILARÉ, Edis. Revista de Direito Ambiental, São Paulo, n. 38, ano 10, abr./jun. 2005.

M ENECHINO, Laila Pacheco; PROCÓPIO, Juliana Barata; VIANNA, Camillo Kemmer. Loteamentos irregulares em áreas de preservação permanente e seus impactos sócioambientais. In: FERREIRA, Yoshiya Nakagawara et al. (Coord.). Anais do II Seminário Nacional sobre Regeneração Ambiental de Cidades. Londrina: UEL, 2007.

MUKAI, Toshio. Direito urbano-ambiental brasileiro. 2. ed. rev. atual. e ampl. São Paulo: Dialética, 2002.

PRESTES, Vânesca Buzelato. A resolução CONAM A n. 369/2006 na perspectiva do direito intertemporal: a hipótese da regularização fundiária sustentável. In: BENJ AM IN, Antonio Herman; LECEY, Eladio; CAPPELLI, Silvia (Org.). Congresso Internacional de Direito Ambiental. M eio ambiente e acesso a Justiça: flora, reserva legal e APP. 3v. São Paulo: Imprensa Oficial do Estado de São Paulo, 2007.

. Municípios e meio ambiente: a necessidade de uma gestão urbano-ambiental. In: PRESTES, Vânesca Buzelato (Org.). Temas de direito urbano-ambiental. Belo Horizonte: Fórum, 2006.

SILVA, Jacqueline Severo da. Regularização Fundiária: avanços e perspectivas, a experiência de Porto Alegre. Revista da Procuradoria-Geral do M unicípio de Porto Alegre, Porto Alegre, n. 15, dez. 2001. Disponível em:

বtttp://www2.portoalegre.rs.gov.br/pgm/default.php?reg=5\&p_secao $=12>$. Acesso em: 08 maio 2008.

SILVA, José Afonso da. Curso de Direito Constitucional Positivo. 24. ed. rev. e atual. nos termos da Reforma Constitucional. São Paulo: Malheiros, 2005.

. Direito Ambiental Constitucional. 5. ed. São Paulo: M alheiros, 2004.

STEIGLEDER, Annelise M onteiro. Responsabilidade Civil Ambiental: as dimensões do Dano Ambiental no Direito Brasileiro. Porto Alegre: Livraria do Advogado Ed., 2004.

TEIXEIRA, Orci Paulino Bretanha. O Direito ao M eio Ambiente ecologicamente equilibrado como direito fundamental. Porto Alegre: Livraria do Advogado Ed., 2006. 